\title{
TWO CANALS IN MAXILLARY FIRST MOLAR: A RARE DENTAL ENTITY
}

\author{
Dileep Soni' ${ }^{1}$ Ankita Beniwal2, Rakesh Jain ${ }^{3}$, Pratima Swarnkar 4 , Ritu Meel ${ }^{5}$ \\ ${ }_{1}^{1}$ MDS, Department of Conservative Dentistry \& Endodontics, Mahatma Gandhi Dental College \& Hospital, Sitapura, Jaipur. \\ 2 Post Graduate Student, Department of Pedodontics, Mahatma Gandhi Dental College \& Hospital, Sitapura, Jaipur. \\ ${ }_{3}^{3}$ Post Graduate Student, Department of Preventive \& Community Dentistry, Mahatma Gandhi Dental College \& Hospital, \\ Sitapura, Jaipur. \\ ${ }^{4} M D S$, Department of Pedodontics, Mahatma Gandhi Dental College \& Hospital, Sitapura, Jaipur. \\ 5Post Graduate Student, Department of Conservative Dentistry \& Endodontics, Mahatma Gandhi Dental College \& Hospital, \\ Sitapura, Jaipur.
}

\section{ABSTRACT}

Root anatomy studies were divided into laboratory studies (In-Vitro), clinical root canal system anatomy studies (In vivo) and clinical case reports of anomalies. Over 95\% (95.9\%) of maxillary first molars had three roots and 3.9\% had two roots. The incidence of fusion of any two or three roots was approximately 5.2\%. Conical and C-shaped roots and canals were rarely found (0.12\%).The fusion of the two buccal roots has the prevalence of $0.4 \%$ in maxillary first molars. Nevertheless, presence of only one buccal root with one canal is extremely rare.

\section{KEYWORDS}

Maxillary First Molar, Two Canal, Two Root, Spiral Ct.

HOW TO CITE THIS ARTICLE: Soni D, Beniwal A, Jain R, et al. Two canals in maxillary first molar: a rare dental entity. J Evolution Med Dent Sci 2016;5(2):161-164, DOI: 10.14260/jemds/2016/37

\section{INTRODUCTION}

Successful root canal therapy requires a thorough knowledge of root and root canal morphology. It is generally accepted that the most common form of the permanent maxillary first molar has one two, three, four roots and one two, three, four and multiple canals. ${ }^{1}$

It is common knowledge that the goal of each root canal treatment therapy is the thorough cleaning and shaping or obturation of the entire root canal system. The main reasons for endodontic failure are apical percolation and the presence of microorganisms caused by incomplete instrumentation, inadequate cleaning, insufficient canal obturation, and the presence of untreated canals. ${ }^{2}$ The clinical methods include clinical evaluation during endodontic treatment using magnification or a surgical operating microscope (SOM).2,3,4

Two-rooted maxillary first molar with two canals has rarely been reported. Such an anatomic variation has been reported in a limited number of studies for second maxillary molar. The present case report maxillary first molars with fusion of the two roots and two canals.

\section{CASE REPORT}

A 56-year-old female presented to the Department of endodontic, with a chief complaint of spontaneous toothache in her maxillary left first molar for the previous five days. The patient's medical history was unremarkable. The tooth was sensitive to temperature variations and electric pulp test and tender to vertical percussion. The pre-operative radiograph on maxillary left first molar (Figure 1).

Financial or Other, Competing Interest: None.

Submission 01-12-2015, Peer Review 02-12-2015,

Acceptance 31-12-2015, Published 07-01-2016.

Corresponding Author:

Dr. Dileep Soni,

B-401 Maharaja Apartment,

Opposite Chinkara Canteen Banipark,

Jaipur-302016.

E-mail: dileep01.soni@gmail.com

DOI: $10.14260 /$ jemds/2016/37
The tooth was diagnosed with irreversible pulpitis with apical periodontitis. Local anesthesia was administered with 2\% lidocaine and 1:80000 epinephrine and a rubber dam was placed. After removal of caries the pulp chamber was completely rinsed with normal saline. Exploration of the root canal orifices resulted in finding one buccal and two palatal orifice (Initially). Clinical image of buccal orifice was relatively large (Figure 2). No extra orifice was found by further exploration. The morphology was confirmed by further radiographic examination as initial radiographs were unclear. The root canals were explored with a K-Flexofile ISO-20 (DENTSPLY) and their lengths were determined by a Root-ZX apex locator (Morita, Tokyo, Japan) and confirmed with an intra-oral periapical radiograph (Figure 3). To confirm the presence of the two canal and roots morphology in the Spiral Computed Tomography (SCT) was scheduled. To ascertain more precisely the 3-dimensional (3D) relationship of the tooth structure, CT imaging was performed using the 3D (General Electric, Siemens, 64 slices, 120 kV, 90 am). From the $3 \mathrm{D}$ reconstruction (interval of $0.6 \mathrm{~mm}$ ) image it was confirmed that the tooth maxillary left first molar revealed 2 separate orifices indicating 2 separate canals(one buccal and one palatal) in the two root. (Figure-4 a,b,c,d).

The canals were then further prepared with Protaperrotary files (DENTSPLY) with 0.04 taper using the crowndown technique. During root canal preparation, irrigation was performed using normal saline, $2.5 \%$ sodium hypochlorite solution, and $17 \%$ EDTA. The canals were dried with absorbent paper points (DENTSPLY) (Figure-5) and obturated using lateral condensation of gutta-percha (DENTSPLY,) and AH26 resin sealer (DENTSPLY). Obturation quality was confirmed radiographically (Figure-6). Access cavity was then sealed with a temporary restorative material. Post restorative treatment given in this tooth. 


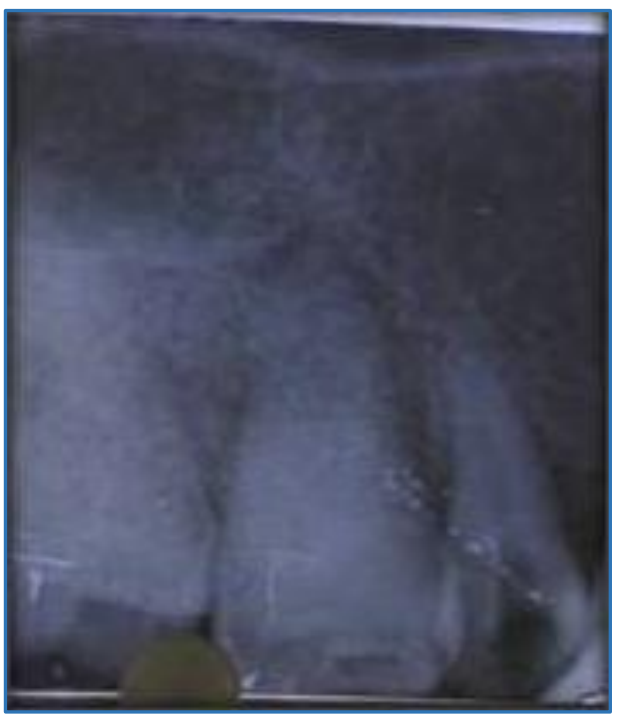

Fig. 1: Pre-Operative $r / g$

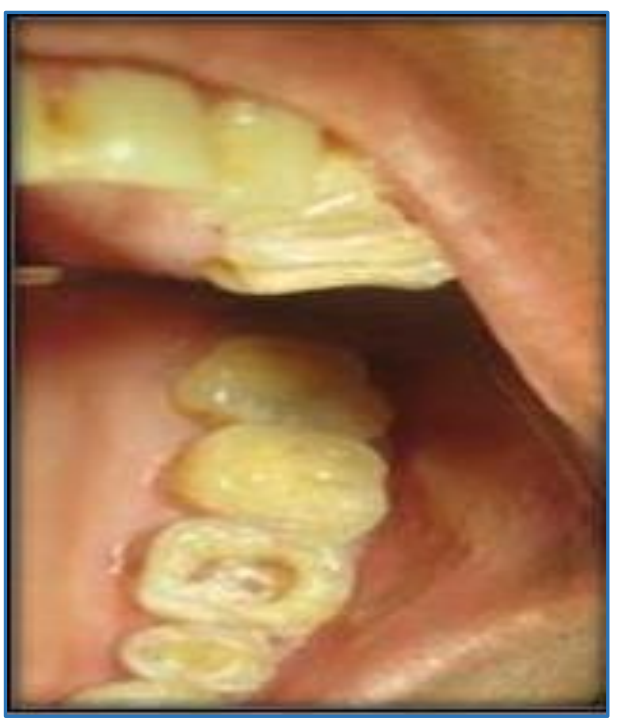

Fig. 2: Clinical Photograph

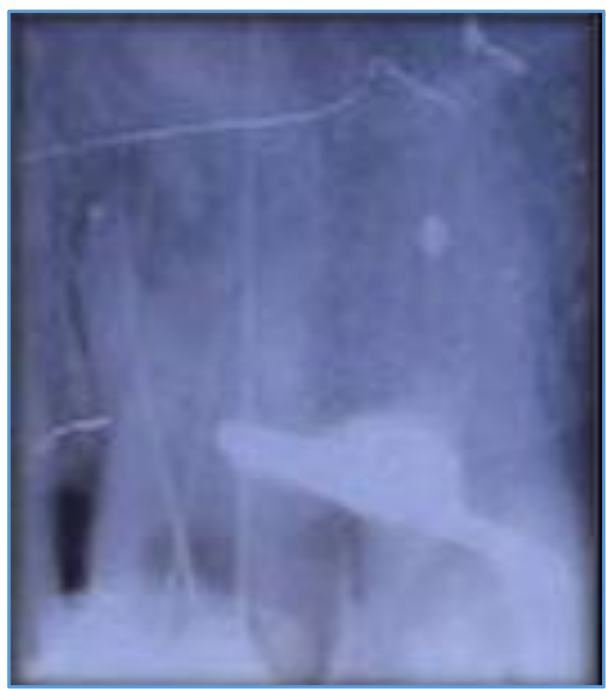

Fig. 3: $W L r / g$

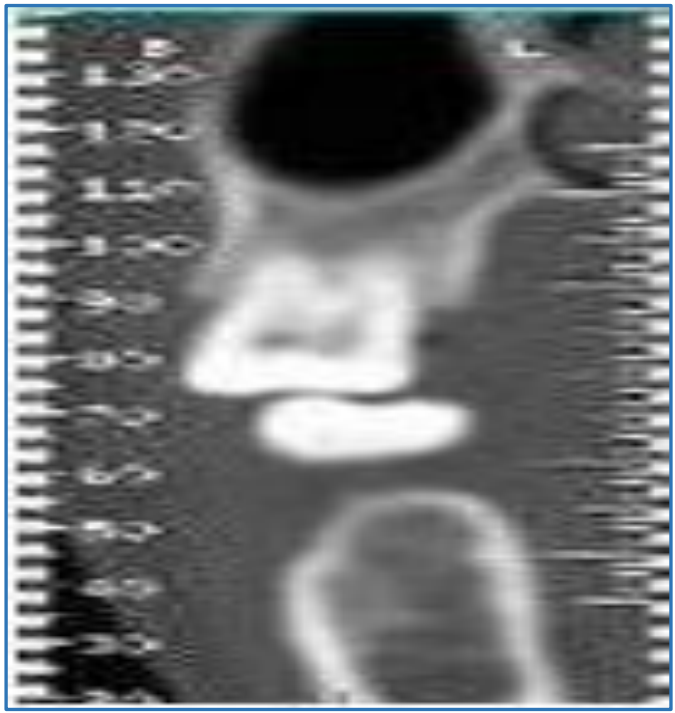

Fig. 4(a): SCT View

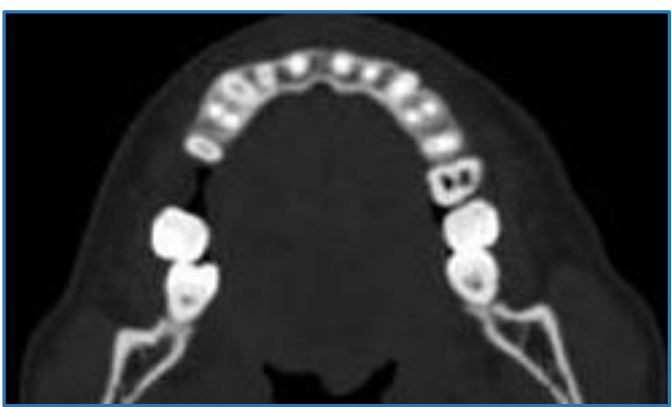

Fig. 4(b): SCT Coronal View

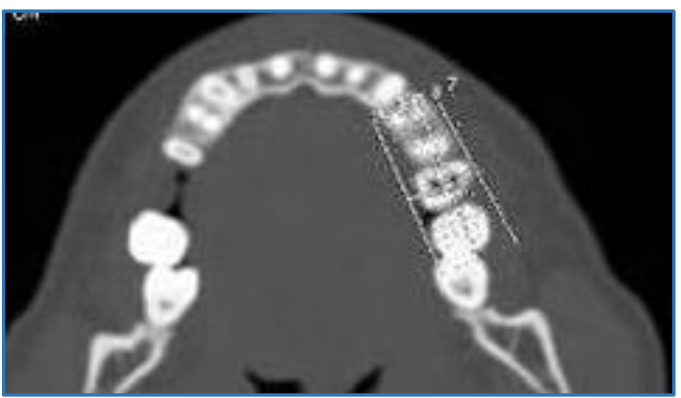

Fig. 4(C): CT Middle View

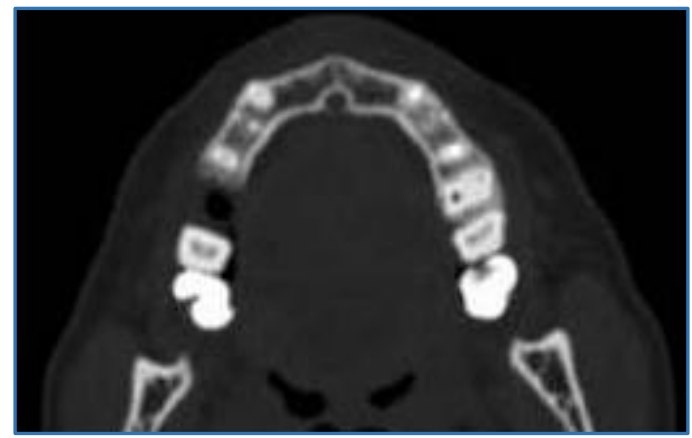

Fig. 4(d): SCT Apical View 


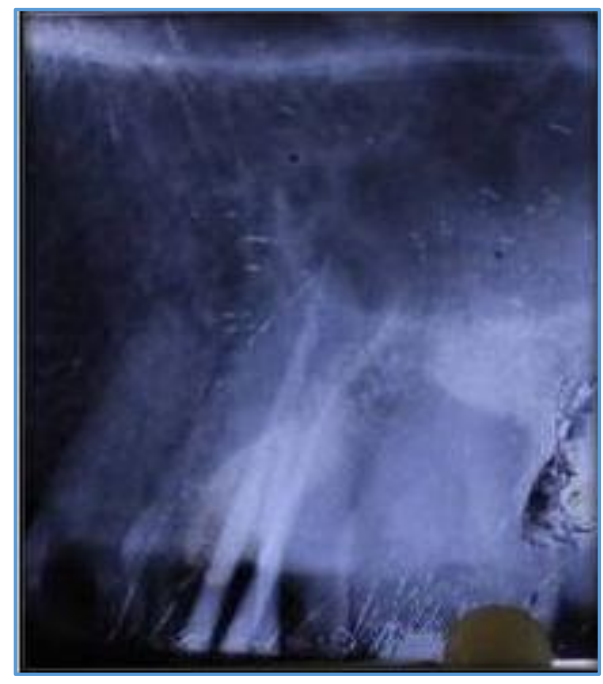

Fig. 5: Master Cone $\mathrm{r} / \mathrm{g}$

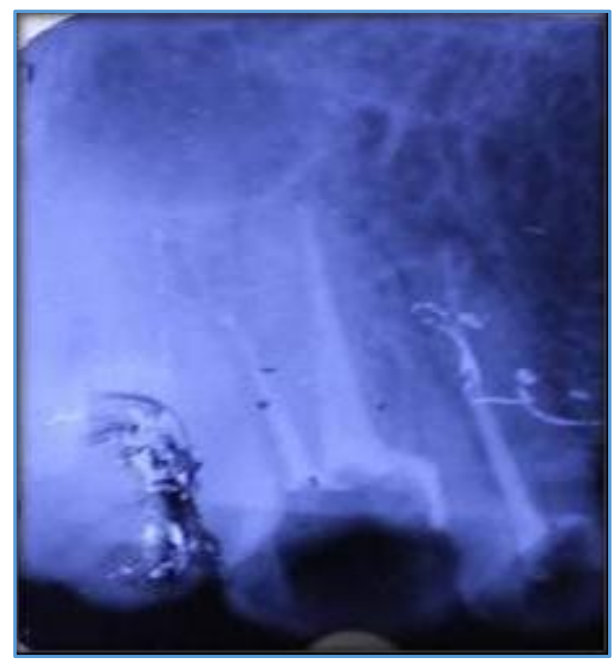

Fig. 6: Post Obturation $r / g$

\section{DISCUSSION}

Based on the dental literature and this series of clinical cases, it is evident that knowledge of the anatomic morphology of the maxillary molars is essential for the success of endodontic treatment. This article presents case with an unusual number or arrangement of two canals. Even if the incidence of two canals or roots might be very low and has been rarely described during the endodontic treatment.

The present paper describes the nonsurgical endodontic management of an unusual maxillary first molar with two roots with two canals. This case is considerable because of having one palatal canals in a palatal root and one buccal canal in a buccal root. Cleghorn et al. (2006) conducted a comprehensive review of the root and root canal morphology of the maxillary first molar. ${ }^{1}$

The 2-rooted type of the maxillary first molar is rarely reported. Its incidence in the literature is $3.9 \% .{ }^{1}$ The fusion of the two buccal roots has the prevalence of $0.4 \%$ in maxillary first molars. ${ }^{5}$ Fava (2001) reported a case of maxillary first molar with two roots; two canals in the buccal root (Vertucci type IV) and one palatal root canal. ${ }^{5}$ Nevertheless, presence of only one buccal root with one canal is extremely rare. ${ }^{5}$ Gopikrishna et al. (2008) presented the endodontic management of a maxillary first molar with a single-fused buccal root with two canals and 2 palatal roots. ${ }^{6}$ After confirmation of this unusual morphology by spiral computerized tomography, incidentally they mentioned that the other maxillary first molar in their reported patient had also a similar morphology, but it had only one buccal canal in its single buccal root.6,7 Radiographs produce only a 2dimensional image, resulting in superimposition and distortion. Since it cannot be useful in cases with complex root canal anatomy, it is crucial to use all of the armamentaria to diagnose and treat the entire root canal system.8,9 According to previous studies. ${ }^{7}$ where Computerized Tomography (CT) was used for definitive diagnosis of morphologic abnormalities in the root canal anatomy. ${ }^{10}$ spiral CT of the involved tooth was conducted in the present case.

\section{CONCLUSION}

Clinicians must have adequate knowledge about root canal morphology and its variations. The location and morphology of root canals should be evaluated by radiography before and during root canal treatment. Careful examination of radiographs and the internal anatomy of teeth are essential for successful treatment. Thorough knowledge of root and root canal morphology and a good anticipation of their possible morphologic variations are essential and will help to reduce endodontic failure caused by incomplete root canal preparation and obturation. The increased magnification of the operating field has many benefits, both for the operator and the patient and nowhere more so than in endodontic.

The ability to work with a high level of accuracy and control improves the quality of treatment, reduces treatment time and reduces operator fatigue. A combination of diagnostic tools will help us diagnosis of canal and root morphology earlier and detect failing restorations sooner, all to avoid more costly, destructive dental procedures and -"Truly take dentistry into the preventive rather than the reactive mode."1

\section{REFERENCES}

1. Blaine M Cleghorn, William H Christie and Cecilia CS Dong. Root and root canal morphology of the human permanent maxillary first molar: A Literature Review; J Endod 2006;32(9):813-820.

2. Silke Holderrieth and Christian Ralf Gerhardt. Maxillary molars with morphologic variations of the palatal root canals: A Report of Four Cases J Endod 2009;35(7):1060-1065.

3. Buhrley LJ, Barrows MJ, BeGole EA, et al. Effect of magnification on locating the MB2 canal in maxillary molars. J Endod 2002;28:324-327.

4. Neaverth EJ, Kotler LM, Kaltenbach RF. Clinical investigation (In vivo) of endodontically treated maxillary first molars. J Endod 1987;13:506-512.

5. LRG Fava Root Canal Treatment in an unusual maxillary first molar-A case report.

Int endod J 2001;34(8):649-653.

6. Gopikrishna V, Reuben J and Kandaswamy D. "Endodontic management of a maxillary first molar with two palatal roots and a single fused buccal root diagnosed with spiral computed tomography-a case report," Oral Surg Oral Med Oral Pathol 2008;105(4):e74-e78. 
7. Deepalakshmi M, Miglani R, Indira R, et al. "Spiral CT diagnosis and endodontic management of an anatomically variant palatal root with two canals in a maxillary first molar." Indian J of Dent Res 2010;21(3):443-445.

8. Aggarwal V, Singla M, Logani A, et al. "Endodontic management of a maxillary first molar with two palatal canals with the aid of spiral computed tomography: a case report." J Endod 2009;35(1):137-139.
9. Vertucci FJ. "Root canal morphology and its relationship to endodontic procedures." Endodontic Topics. 2005;10(1):3-29.

10. Leila Atash Biz Yeganeh, Mamak Adel, Reza Vahedi, et al. Endodontic management of a maxillary first molar with two palatal canals and a single buccal canal: A case report. Case reports in dentistry. Volume 2012;1-4. 